\title{
Cartilage metabolism in the injured and uninjured knee of the same patient
}

\author{
L Dahlberg, H Roos, T Saxne, D Heinegård, M W Lark, L A Hoerrner, L S Lohmander
}

\begin{abstract}
Objective-To examine if unilateral knee injury affects the synovial fluid concentrations of aggrecan fragments, cartilage oligomeric matrix protein (COMP) fragments, stromelysin-1, and tissue inhibitor of metalloproteinases-1 (TIMP-1) in the contralateral uninjured knee.
\end{abstract}

Methods-Synovial fluids from the injured and uninjured knees were obtained at different times in a group of patients after unilateral knee trauma. Serum samples were obtained on the same occasion. Concentrations of aggrecan fragments were determined by precipitation with Alcian Blue; those of COMP fragments, stromelysin-1, and TIMP-1 were measured by immunoassay. Concentrations were compared with those in a reference group of 10 healthy volunteers.

Results-Immediately after knee injury, concentrations of aggrecan fragments, COMP fragments, stromelysin-1 and TIMP-1 were increased in the synovial fluid of the injured knee. However, concentrations of aggrecan and COMP fragments, and stromelysin-1 increased also in the contralateral uninjured knee immediately after injury, but less than in the injured knee. Subsequently, the concentrations of all markers decreased in the synovial fluid of the injured knee, but remained unchanged in the uninjured knee. The concentration of aggrecan fragments in the injured knee decreased to less than that in the uninjured knee in the chronic phase. Serum concentrations of COMP were much smaller than those in synovial fluid.

Conclusions-The increased concentrations of aggrecan and COMP fragments and stromelysin-1 in the joint fluid of the contralateral, uninjured knee following unilateral knee injury, compared with concentrations in healthy reference knees, suggest changes in joint cartilage metabolism in both knees following unilateral knee injury. The mechanisms for these changes are unclear. The low serum concentration of COMP makes it less likely that there is any significant 'exchange' of molecular markers between the knees. A further consequence of these findings is that the contralateral knee cannot be recommended as the only control joint in studies of matrix metabolism in patients with unilateral knee injury.

(Ann Rheum Dis 1994; 53: 823-827)
Joint cartilage matrix macromolecules and proteases involved in cartilage matrix metabolism are continuously released into the synovial fluid. We have previously shown increased concentrations of aggrecan fragments, stromelysin-1, tissue inhibitor of metalloproteinases-1 (TIMP-1), and cartilage oligomeric matrix protein (COMP) in synovial fluid from patients with knee injury, both early and late after joint trauma. ${ }^{1-5}$ These studies have shown significant changes in concentrations of cartilage matrix molecules and proteases which correlate with joint pathology. This suggests that matrix molecules in joint synovial fluid may be used as markers for changes in cartilage metabolism in joint disease, such as osteoarthritis (OA).$^{6-9}$

An injured knee has an increased risk for developing OA. ${ }^{10-12}$ It has been shown that patients with unilateral knee injury have an altered gait in both limbs. ${ }^{13-15}$ Furthermore, animal models of post-traumatic OA have indicated increased cartilage metabolism in the injured joint, ${ }^{16} 17$ in addition to the contralateral, uninjured joint. ${ }^{17-19}$

To examine if a unilateral knee injury in the human causes changes in the concentrations of cartilage markers in the joint fluid of the contralateral uninjured knee, we measured the concentrations of aggrecan fragments, COMP fragments, stromelysin-1, and TIMP-1 in synovial fluids from both the injured and uninjured knees of 54 patients. Results were compared with concentrations of markers in knee synovial fluids from 10 healthy volunteers. The study was approved by the ethics committee of the Medical Faculty of Lund University.

\section{Patients and methods}

\section{PATIENTS}

The study included 54 patients with acute or previous trauma to one knee and no earlier known trauma to the other knee. Patients were examined by arthroscopy and radiography of the injured but not the uninjured knee. Synovial fluids were aspirated from the injured and uninjured knee before the arthroscopy, and on the same occasion a serum sample was obtained. Aspiration of joint fluid was equally successful in both the injured and uninjured knees. Only patients without any radiographic signs of knee $\mathrm{OA},{ }^{20}$ and from whom paired joint fluid samples were obtained, were included. The patients were assigned to one of three groups with respect to time after the trauma (the time when the symptoms of the injured knee started): the acute group (11 patients with samples obtained up to four
L A Hoerrner

Correspondence to: Dr Dahlberg.

Accepted for publication 28 June 1994 
Table 1 Number of patients (n), time since trauma

(Time), and volume (Vol.) of aspirated synovial fluid from the injured and uninjured knee in the four study groups

\begin{tabular}{lcccl}
\hline & Acute & Subacute & Chronic & Reference \\
\hline $\mathrm{n}$ & 11 & 14 & 29 & 10 \\
Age (yr) & 24 & 18 & 22 & 25 \\
& $\mathbf{2 7}$ & $\mathbf{2 8}$ & $\mathbf{2 8}$ & $\mathbf{2 8}$ \\
& 35 & 40 & 37 & 32 \\
Time (weeks) & 1 & 8 & 123 & \\
& $\mathbf{1 . 4}$ & $\mathbf{1 4}$ & $\mathbf{1 7 8}$ & \\
& 3 & 23 & 208 & \\
Vol. injured (ml) & 7.5 & 0.5 & 0.6 & \\
& $\mathbf{1 5}$ & $\mathbf{1 . 5}$ & $\mathbf{1}$ & \\
& 18.5 & 5 & 2.3 & \\
Vol. uninjured (ml) & 0.5 & 0.3 & 0.5 & 0.9 \\
& $\mathbf{0 . 7}$ & $\mathbf{0 . 7}$ & $\mathbf{1}$ & $\mathbf{2 . 5}$ \\
& 1.9 & 1.8 & 2 & 4
\end{tabular}

*Age at time of injury. For definition of groups see Patients and methods.

Age, time, and volume are given as the 25 th percentile value at the top, median value (bold) in the middle, and 75 th percentile value at the bottom.

weeks after the knee trauma), the subacute group (samples obtained 4-52 weeks after trauma) or the chronic group (samples obtained more than 52 weeks after trauma) (table 1).

Arthroscopy showed a combination of cruciate ligament, collateral ligament and meniscus injuries in 31 patients. Fifteen patients had isolated meniscus injuries, and eight patients had cartilage lesions without ligament injuries. The different injuries were equally distributed in the three groups. Four of the patients with cruciate ligament injury had undergone ligament reconstruction more than three years before the sampling. Thirty four patients did not have any arthroscopic cartilage changes. The remaining patients had fibrillations and occasional clefts in the joint cartilage surface in one knee compartment, but normal radiographic findings.

Ten healthy athletes without knee symptoms and with no previous knee injury were used as a reference group ${ }^{3-5}$ (table 1 ).

Table 2 Synovial fluid aggrecan (AGN) fragments, COMP, stromelysin-1 (SLN) and TIMP-1 concentrations in synovial fluid of the injured and uninjured knee in the study groups, and serum COMP concentrations

\begin{tabular}{|c|c|c|c|c|c|c|c|}
\hline & \multicolumn{3}{|l|}{ Injured } & \multicolumn{3}{|c|}{ Uninjured } & \multirow[b]{2}{*}{ Reference } \\
\hline & Acute & Subacute & Chronic & Acute & Subacute & Chronic & \\
\hline $\begin{array}{l}\text { Synovial fluid } \\
\text { n } \\
\text { AGN }(\mu \mathrm{g} / \mathrm{ml})\end{array}$ & $\begin{array}{r}11 \\
98 \\
133 \\
387\end{array}$ & $\begin{array}{r}14 \\
50 \\
103 \\
164\end{array}$ & $\begin{array}{l}29 \\
43 \\
54 \\
70\end{array}$ & $\begin{array}{r}11 \\
59 \\
75 \\
140\end{array}$ & $\begin{array}{l}14 \\
42 \\
72 \\
86\end{array}$ & $\begin{array}{l}29 \\
58 \\
76 \\
98\end{array}$ & $\begin{array}{r}9 \\
14 \\
52 \\
67\end{array}$ \\
\hline $\mathrm{n}$ COMP $(\mu \mathrm{g} / \mathrm{ml})$ & $\begin{array}{r}11 \\
115 \\
130 \\
172\end{array}$ & $\begin{array}{r}13 \\
70 \\
102 \\
145\end{array}$ & $\begin{array}{r}27 \\
62 \\
89 \\
115\end{array}$ & $\begin{array}{r}11 \\
93 \\
124 \\
136\end{array}$ & $\begin{array}{r}13 \\
77 \\
113 \\
138\end{array}$ & $\begin{array}{r}27 \\
79 \\
92 \\
111\end{array}$ & $\begin{array}{r}6 \\
16 \\
43 \\
73\end{array}$ \\
\hline$\stackrel{\mathrm{n}}{\mathrm{SLN}}(\mathrm{nmol} / \mathrm{l})$ & $\begin{array}{r}7 \\
50 \\
191 \\
474\end{array}$ & $\begin{array}{l}7 \\
0 \cdot 1 \\
2 \cdot 6 \\
95\end{array}$ & $\begin{array}{c}24 \\
2 \cdot 6 \\
8 \\
18\end{array}$ & $\begin{array}{l}7 \\
4 \cdot 1 \\
6 \cdot 7 \\
14\end{array}$ & $\begin{array}{l}7 \\
0 \cdot 2 \\
3 \cdot 5 \\
6 \cdot 1\end{array}$ & $\begin{array}{l}24 \\
1 \cdot 7 \\
5 \cdot 6 \\
8\end{array}$ & $\begin{array}{l}10 \\
0 \cdot 4 \\
2 \\
4 \cdot 8\end{array}$ \\
\hline$\stackrel{\mathrm{n}}{\mathrm{TIMP}-1(\mathrm{nmol} / \mathrm{l})}$ & $\begin{array}{r}7 \\
42 \\
69 \\
135\end{array}$ & $\begin{array}{l}8 \\
5 \cdot 9 \\
7 \cdot 5 \\
18\end{array}$ & $\begin{array}{r}24 \\
5 \cdot 9 \\
7 \cdot 5 \\
9 \cdot 2\end{array}$ & $\begin{array}{l}7 \\
6 \cdot 5 \\
6 \cdot 7 \\
8 \cdot 3\end{array}$ & $\begin{array}{l}8 \\
4 \cdot 4 \\
4 \cdot 7 \\
5 \cdot 7\end{array}$ & $\begin{array}{c}24 \\
5 \cdot 9 \\
6 \cdot 6 \\
7 \cdot 3\end{array}$ & $\begin{array}{l}10 \\
0 \cdot 5 \\
4 \cdot 8 \\
8 \cdot 5\end{array}$ \\
\hline $\begin{array}{l}\text { Seryum } \\
\text { n } \\
\text { COMP }(\mu \mathrm{g} / \mathrm{ml})\end{array}$ & $\begin{array}{c}11 \\
5 \cdot 1 \\
7 \cdot 3 \\
8 \cdot 4 \\
\end{array}$ & $\begin{array}{c}14 \\
7 \cdot 2 \\
7 \cdot 9 \\
9 \cdot 5 \\
\end{array}$ & $\begin{array}{l}29 \\
6 \cdot 5 \\
7 \cdot 8 \\
9 \cdot 2 \\
\end{array}$ & & & & $\begin{array}{r}10 \\
9 \cdot 1 \\
10 \cdot 6 \\
11 \cdot 5 \\
\end{array}$ \\
\hline
\end{tabular}

$\mathrm{n}=$ Number of patients; for definition of groups, see Patients and methods.

The total number of samples analysed with each method differs because of lack of fluid. Concentrations for each marker are given as the 25 th percentile value at the top, median value (bold) in the middle, and 75 th percentile value at the bottom.
SAMPLE PREPARATION

Synovial fluid was aspirated with a $1.2 \mathrm{~mm}$ needle and a lateral parapatellar approach. The joint fluids were aspirated to dryness and the volumes recorded. The serum and joint fluid samples were centrifuged and then stored at $-70^{\circ} \mathrm{C}$ until analysed.

MARKER ASSAYS

Aggrecan fragment concentrations were determined by precipitation of chondroitinand keratan sulphate-containing proteoglycan fragments with Alcian Blue. ${ }^{21}$

Stromelysin-1 and TIMP-1 concentrations were measured by sandwich immunoassay, using monoclonal and polyclonal antibodies. $^{222} 23$ The assay for stromelysin-1 detects the proform of the enzyme, the large molecular active form and the enzyme complexed to TIMP-1, but not small molecular forms or enzyme complexed to $\alpha$-2-macroglobulin. The large majority of the enzyme is in the proform. ${ }^{23}$ The assay for TIMP-1 detects free TIMP-1 but not the inhibitor complexed with metalloproteinases.

COMP concentrations in synovial fluid and serum were determined by a competition immunoassay. ${ }^{24}$ Antibodies were raised in a rabbit immunised with purified bovine COMP. Microtitre plates were coated with human COMP and a set of standards using different concentrations of human COMP was included in each plate.

\section{STATISTICAL ANALYSIS}

Wilcoxon's matched pairs signed ranks test was used to examine differences between injured and uninjured knees. Mann-Whitney rank sum test for two independent samples was used to calculate differences between the reference group and the injured and uninjured knees. For correlation analysis the Spearman rank correlation method was used. $p<0.05$ was considered significant. All differences and correlations discussed as such are statistically significant at this level or better.

\section{Results}

Marker concentrations in the ipsi- and contralateral knees are presented individually, and as median concentration values. Because of lack of fluid, the number of analyses differs between markers. Median concentrations of each marker, however, were calculated using only paired samples (table 2).

There was no difference regarding sex and age distribution between the three study groups, or between these groups and the reference group (table 1 ). The specific type of knee injury, the degree of arthroscopic cartilage damage, or cruciate ligament reconstruction, did not significantly influence median marker concentrations in these small groups of patients. None of the patients was treated with intra-articular glucocorticoids or was receiving chronic treatment with non-steroidal antiinflammatory drugs. 


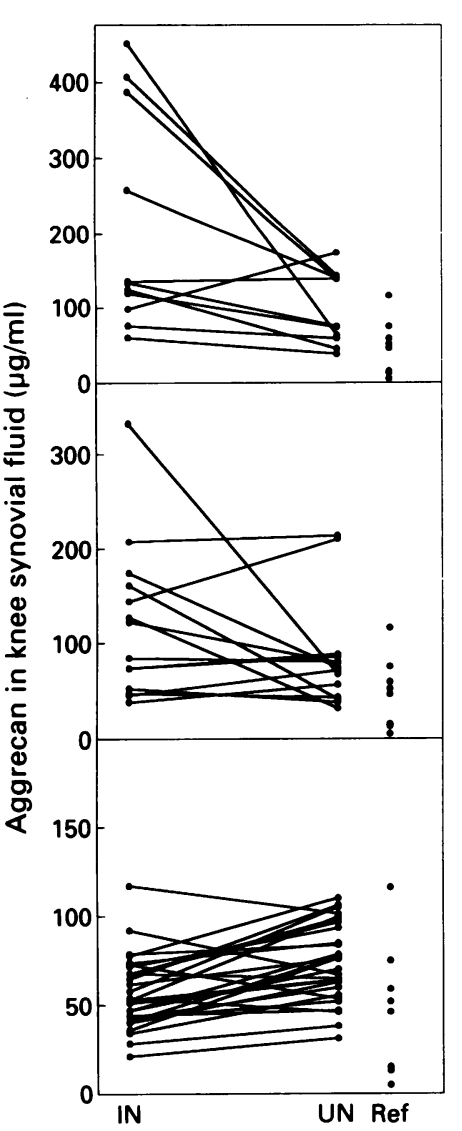

Figure 1 Individual concentration values of aggrecan in synovial fluid in the injured and uninjured knee. Top: acute group; middle: subacute group; bottom: chronic group. UN, uninjured knee; IN, injured knee; Ref, individual concentration values in the reference group.

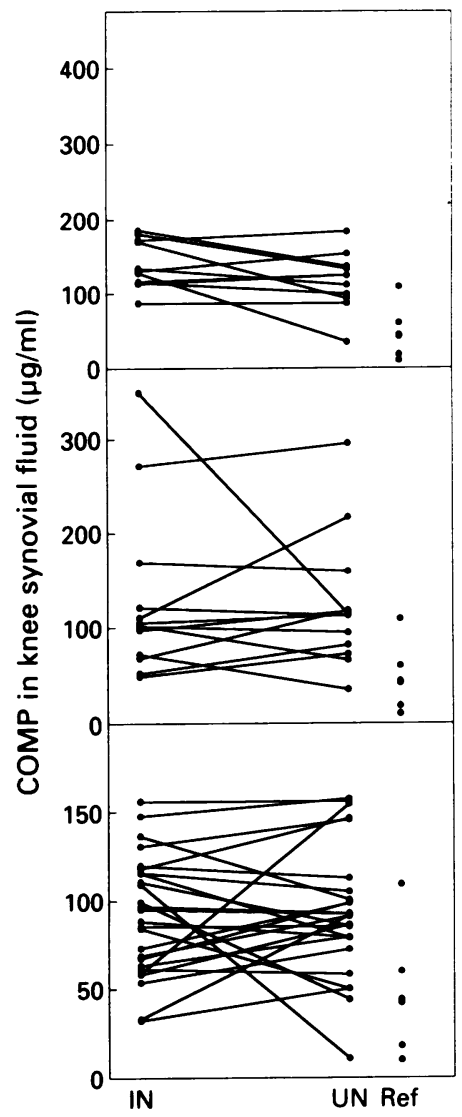

Figure 2 Individual concentration values of COMP in synovial fluid in the injured and uninjured knee. Top: acute group; middle: subacute group; bottom: chronic group. UN, uninjured knee; IN, injured knee; Ref, individual concentration values in the reference group.

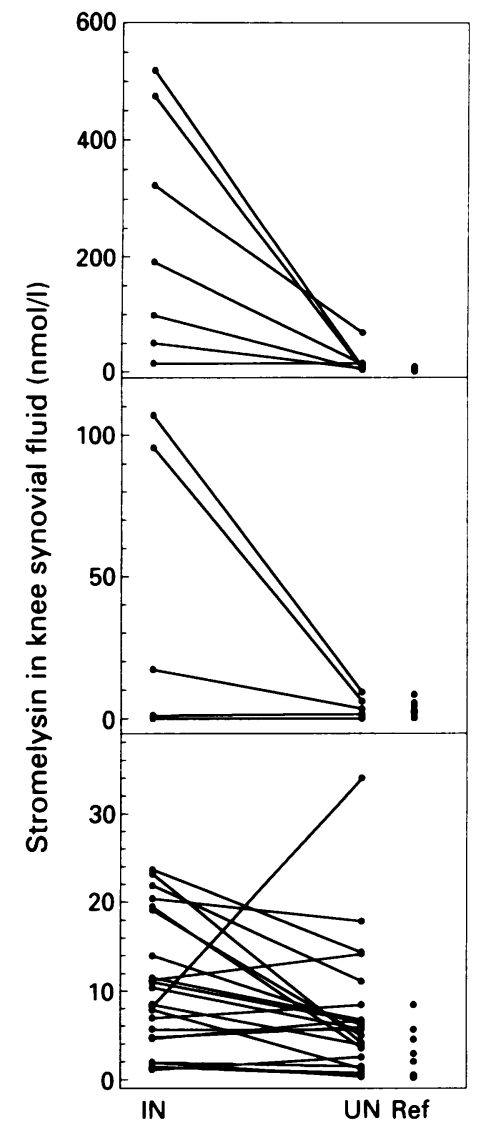

Figure 3 Individual concentration values of stromelysin-1 in synovial fluid in the injured and uninjured knee. Top: acute group; middle: subacute group; bottom: chronic group. UN, uninjured knee; $I N$, injured knee; Ref, individual concentration values in the reference group. There is an overprojection of one line at the bottom.
INJURED KNEES COMPARED WITH REFERENCE KNEES

In the acute phase in the injured knee, the concentrations of all markers, aggrecan fragments, COMP fragments, and stromelysin-1 and TIMP-1 were greater than in the reference group (figs $1-3$, table 2 ). With increased time after injury, the concentrations of markers in the injured knee decreased, although COMP, stromelysin-1 and TIMP-1 concentrations were still increased compared with reference values in the chronic phase (figs 1-3, table 2).

UNINJURED KNEES COMPARED WITH REFERENCE KNEES

In the acute phase in the uninjured knee, the joint fluid concentrations of aggrecan fragments, COMP fragments, and stromelysin-1 were higher than in the reference group. The TIMP-1 concentration did not differ from the reference values (figs 1-3, table 2). Unlike the concentrations of markers in the injured knee, there was no significant change in joint fluid marker concentrations in the uninjured knee over time. Thus concentrations of aggrecan fragments, COMP fragments, and stromelysin-1 were increased compared with reference values in the chronic phase also (figs 1-3, table 2).
The ratios of aggrecan to COMP were similar in the acute, subacute and chronic phases in both the injured and uninjured knee, and did not differ from the reference ratio (data not shown). Furthermore, in the chronic phase, there was a correlation between the concentrations of aggrecan and COMP fragments in both the injured and uninjured knees. There was no correlation between stromelysin-1 and aggrecan fragment concentrations (data not shown). This may be because the assay used also detects the proform of the enzyme, and most of the enzyme in joint fluid is present in the proform. ${ }^{23}$

\section{COMPARISON BETWEEN INJURED AND}

UNINJURED KNEES

In the acute phase, the injured knee had greater concentrations of aggrecan fragments, stromelysin-1, and TIMP-1 compared with the uninjured joint. However, concentrations of COMP did not differ between the knees (figs 1-3, table 2).

In the subacute phase, the concentrations of aggrecan and COMP fragments and stromelysin-1 were similar in both knees, but TIMP-1 concentrations were greater in the injured knee (figs $1-3$, table 2 ). 


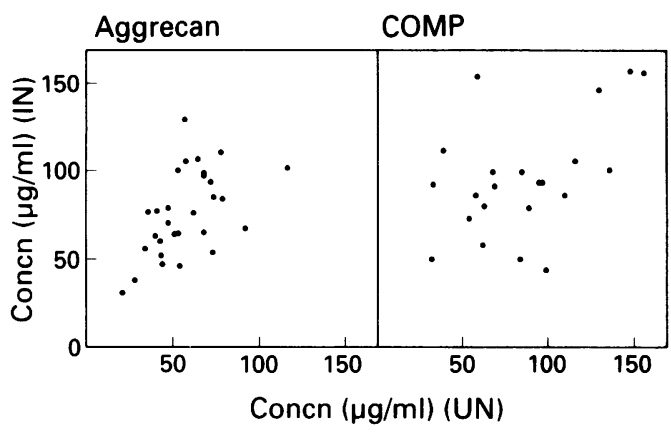

Figure 4 Relation between the uninjured and injured knee with respect to concentrations of aggrecan $(r=0.58)$ and $\operatorname{COMP}(r=0.41)$ in the chronic phase.

In the chronic phase, the injured knee had a smaller median concentration of aggrecan fragments, COMP concentrations did not differ, and stromelysin-1 and TIMP-1 concentrations were greater in the injured knee (figs $1-3$, table 2).

In the chronic phase, there was a correlation between the injured and uninjured knees with respect to both aggrecan fragment and COMP concentrations (fig 4).

Serum COMP concentrations were approximately $10 \%$ of the joint fluid COMP concentrations (table 2). There was no difference in the serum COMP concentrations between the acute, subacute, and chronic phases. Serum and joint fluid COMP concentrations did not correlate.

When the data were expressed as total content of synovial fluid markers (calculated as the product between the concentration of the marker and the aspirated synovial fluid volume) rather than as concentration values, similar results were obtained. However, in common with findings in previous studies, there was a greater variability in these values, as a result of uncertainties in estimates of total joint fluid volume (data not shown). ${ }^{25}$

\section{Discussion}

The temporal patterns of marker concentrations in the synovial fluid in the injured knee of the patients with unilateral knee injury in the present study is in agreement with those previously reported for post-traumatic patients. ${ }^{13-5}$ However, in the present study we also examined marker concentrations in the contralateral, uninjured knee in the same patients. We found increased concentrations of aggrecan and COMP fragments, and of stromelysin-1 in the synovial fluid of the uninjured knee both early and late after the trauma. These findings may be consistent with an altered matrix metabolism not only in the injured, but also in the uninjured knee. This would corroborate previous investigations in post-traumatic animals in which studies of radioisotope incorporation in the joint cartilage and aggrecan concentration in synovial joint fluids have indicated an altered cartilage metabolism in the unoperated contralateral knee joint. ${ }^{17-19}$

Recently, two studies have compared injured and uninjured human knees with respect to the synovial fluid content of several different aggrecan epitopes. ${ }^{26} 27$ Results were variable, but indicated a greater content of chondroitin sulphate epitopes and sulphated glycosaminoglycans in the injured compared with the uninjured knee. To decrease the influence of interindividual variations, we included only patients in whom it was possible to obtain paired, undiluted samples. Further, the patients were assigned to an acute, subacute, or chronic group because of the marked influence of time after injury on marker concentrations shown by our previous studies. ${ }^{13-5}$ Patients with radiographic OA were excluded from our study, since severe cartilage changes were shown to influence concentrations of markers in synovial fluid. ${ }^{28}$ As a final control, we compared the synovial fluid marker concentrations in the injured patients with those in a reference group having healthy knees.

Several factors may influence cartilage matrix metabolism in the uninjured knee of patients with a unilateral knee injury. Gait and biomechanical analyses have shown that patients with unilateral cruciate ligament deficiency prevent the anterior translation and internal-external rotation of the knee by the use of a more flexed hip position in strenuous situations. ${ }^{13}$ Such patients also use antalgic manoeuvres frequently, ${ }^{14}$ and have a bilateral leg impairment in performance tests. ${ }^{15}$ Animal studies have shown that joint loading induces alterations in the articular cartilage, ${ }^{29} 30$ and in a study of aggrecan fragments in joint fluid before and after physical exercise in healthy athletes, the concentration of this marker was moderately increased after exercise. ${ }^{31}$

The low serum concentration of COMP fragments makes it unlikely that matrix fragments in one joint originate from another joint. However, it is possible that cytokines and degraded matrix products released from a diseased joint and transported to other healthy joints by the circulation can be involved in the early initiation of pathological processes in uninjured joints. ${ }^{18}$ This concept is supported by a report that, in mice, intraperitoneal injection of purified cartilage proteoglycans digested with chondroitinase resulted in synovial inflammation and erosion of the articular tissues. ${ }^{32}$

The results of this study suggest an altered cartilage matrix metabolism not only in the injured, but also in the uninjured knee in patients with unilateral knee injury. The pathophysiological significance and the mechanisms responsible for this finding are not understood. However, the contralateral knee cannot be recommended as the only control joint in studies of matrix metabolism in patients with unilateral knee injury.

The helpful cooperation of the staff of the Department of Orthopedics, Lund University Hospital is greatly appreciated, as is the expert technical assistance of Chris Ebner, Elisavet Trigueiros, and Mariette Hallbeck. Supported by the Swedish Medical Research Council, the Medical Faculty of Lund University, The Zoega, Kock, Ax:son Johnson and Procordia, and Österlund Foundations, the King Gustaf $V$ 80-Year and Osterlund Foundations, the King Gustaf $V$ ro-Year Birthday Fund, Svenska Sallskapet for Medicinsk Forskning Stiftelsen for Vanfora i Skåne, Riksförbundet mot Reumatism,
and Merck Research Laboratories. 
1 Lohmander L S, Dahlberg L, Ryd L, Heinegård D. Increased levels of proteoglycan fragments in joint fluid after knee injury. Arthritis Rheum 1989; 32: 1434-42.

2 Lohmander L S, Hoerrner L A, Lark M W. Metalloproteinases, tissue inhibitor and proteoglycan fragments in knee synovial fluid in human osteoarthritis. Arthritis Rheum 1993; 36: 181-9.

3 Lohmander L S, Roos H, Dahlberg L, Hoerrner L A, Lark $M W$. Temporal patterns of stromelysin, tissue inhibitor and proteoglycan fragments in human knee joint fluid after cruciate ligament and meniscus injury. $f$ Orthop Res 1994; 12: 21-8.

4 Lohmander L S, Hoerrner L A, Dahlberg L, Roos H Björnsson S, Lark MW. Stromelysin, tissue inhibitor of metalloproteinases and proteoglycan fragments in human knee joint fluid after injury. $f$ Rheumatol 1993; 20 1362-8.

5 Lohmander L S, Saxne T, Heinegård D. Release of cartilage oligomeric matrix protein (COMP) into joint fluid after injury and in osteoarthrosis. Ann Rheum Dis 1994; 53: 8-13.

6 Heinegård D, Saxne T. Molecular markers of processes in cartilage in joint disease. $B r \mathcal{f} R$ heumatol $1991 ; 30: 21-4$.

7 Lohmander L S. Markers of cartilage metabolism in arthrosis. Acta Orthop Scand 1991; 62: 623-32.

8 Caterson B, Hughes C E, Johnstone B, Mort J S Immunological markers of proteoglycan metabolism in animal and human osteoarthritis. In: Kuettner $\mathrm{K}$ E, Schleyerbach R, Peyron J, Hascall V C, eds. Articular cartilage and osteoarthritis. New York: Raven Press, 1992 415-27.

9 Thonar E J-M A, Manicourt D H, Williams J M, et al. Serum keratan sulfate: a measure of cartilage proteoglycan metabolism. In: Kuettner K E, Schleyerbach R, glycan metabolism. In: Kuettner K E, Schleyerbach R, Peyron J, Hascall V C, eds. Articular cartilage

10 Johnson R J, Kettelkamp D B, Clark W, Leaverton P. Factors affecting late results after meniscectomy. $\mathcal{F}$ Bone Surg 1974; 56-A: 719-29.

11 Sherman M F, Warren R F, Marshall J L, Savatsky G J. A clinical and radiographical analysis of 127 anterio cruciate insufficient knees. Clin Orthop 1988; 227: 229-37.

12 Kannus $P$, Järvinen $M$. Posttraumatic anterior cruciate ligament insufficiency as a cause of osteoarthritis in a knee joint. Clin Rheumatol 1989; 8: 251-60.

13 Andriachi $T$ P Kramer G M Iandon G C. The biomechanics of running and knee injuries. In: Geinerman $\mathrm{G}$, ed. American academy of orthopaedics surgeons symposium on sports medicine: The knee. St Louis: Mosby Co., 1982; 23-32.

14 Murray M P, Giore D R, Sepic S, Mollinger L. Antalgic manoeuvres during walking in men with unilateral knee disability. Clin Orthop 1985; 199: 192-9.

15 Gauffin H, Petterson G, Tegner Y, Tropp H. Function testing in patients with old rupture of the anterior cruciate ligament. Int $\mathcal{F}$ Sports Med 1990; 11: 73-7.

16 Carney S L, Billingham M E J, Muir H, Sandy J D. Demonstration of increased proteoglycan turnover in cartilage explants from dogs with experimental osteoarthritis. F Orthop Res 1984; 2: 201-6.

17 Heinegård D, Inerot S, Wieslander J, Lindblad G. A method for the quantification of cartilage proteoglycan structures liberated to the synovial fluid during developing degenerative joint disease. Scand f Clin Lab Invest 1985; 45: $421-7$.

18 Floman Y, Eyre D R, Glimcher M J. Induction of osteoarthritis in the rabbit knee joint. Biochemical studies on articular cartilage. Clin Orthop 1980; 147: 278-86.

19 Moskowitz R W, Goldberg V M, Malemud C J. Metabolic responses of cartilage in experimentally induced responses of cartilage in experimentally

20 Ahlbäck S. Osteoarthritis of the knee: a radiographic investigation. Acta Radiologica 1968; Suppl 277: 7-72.

21 Björnsson S. Simultaneous preparation and quantitation of proteoglycan by precipitation with Alcian Blue. Analyt Biochem 1993; 210: 282-92.

22 Cooksley S, Hipkiss J B, Tickle S P, et al. Immunoassay for the detection of human collagenase, stromelysin, tissue inhibitor of metalloproteinases (TIMP), and enzymeinhibitor complexes. Matrix 1992; 10: 285-91.

23 Walakovits L A Moore V L, Bhardwaj N, Gallick G S, Lark $M$ W. Detection of stromelysin and collagenase in synovial fluid from patients with rheumatoid arthritis and synovial fluid from patients with rheumatoid arthritis and
posttraumatic knee injury. Arthritis Rheum 1992; 35: posttraum

24 Saxne $T$, Heinegård D. Cartilage oligomeric matrix protein A novel marker of cartilage turnover detectable in synovia fluid and blood. $\mathrm{Br}$ f Rheumatol 1992; 31: 583-91.

25 Geborek P, Saxne T, Heinegärd D, Wollheim F A Measurement of synovial fluid volume using albumin dilution upon intra-articular saline injection. $\mathcal{f}$ Rheumatol 1988; 15: 91-4.

26 Hazell $P$ K, Dent C, Fairclough J A, Bayliss M T Hardingham $T$ E. Changes in chondroitin sulphate Hardingham T E. Changes in chondroitin sulphate structures detected by monoclonal antibodies in synovial

27 Johnstone B, Bullard K, Caterson B, Spezia P, Gillogly S Analysis of markers of cartilage catabolism in synovia fluid from injured and contralateral control knees of patients with ACL injuries. Orthop Trans 1993; 39: 215.

28 Dahlberg L, Ryd L, Heinegård D, Lohmander L S. Proteoglycan fragments in joint fluid: Influence of arthrosis and inflammation. Acta Orthop Scand 1992; 63: 417-23.

29 Kiviranta I, Tammi M, Jurvelin J, Säämänen A-M Helminen $H$. Moderate running exercise augments glycosaminoglycans and thickness of articular cartilage in glycosaminoglycans and thickness of articular cartila

30 Palmoski M, Perricone E, Brandt K D. Development and reversal of a proteoglycan aggregation defect in normal canine knee cartilage after immobilization. Arthritis Rheum 1979; 22: 508-17.

31 Roos H, Dahlberg L, Lohmander L S. Proteoglycan fragments in knee joint fluid after exercise. Scand $\mathfrak{f} \mathrm{Med}$ Sci Sports 1993; 3: 127-30.

32 Glant $T$ T, Mikecz $\mathrm{K}$, Arzoumanian A, Poole A R. Proteoglycan-induced arthritis in BALB/c mice. Arthritis Rheum 1987; 30: 201-12. 